\title{
Spectroscopic evidence of anthropogenic compounds extraction from polymers by fluorescent dissolved organic matter in natural water
}

\author{
M. Miranda \\ mario.luis.miranda.montenegro@uni- \\ oldenburg.de
}

\section{A. Trojzuck \\ D. Voss \\ S. Gassmann \\ O. Zielinski}

\begin{abstract}
Institute for Chemistry and Biology of the Marine Environment, Carl von Ossietzky University of Oldenburg, Schleusenstrasse 1, 26382 Wilhelmshaven, Germany

Air and Water Quality Laboratory, University of Panama, 0824 Panama, Republic of Panama

Jade University of Applied Sciences, Department of Engineering, F.-Paffrath-Str. 101, 26382 Wilhelmshaven, Germany

Institute for Chemistry and Biology of the Marine Environment, Carl von Ossietzky University of Oldenburg, Schleusenstrasse 1, 26382 Wilhelmshaven

Jade University of Applied Sciences, Department of Engineering, F.-Paffrath-Str. 101, 26382 Wilhelmshaven, Germany

Institute for Chemistry and Biology of the Marine Environment, Carl von Ossietzky University of Oldenburg, Schleusenstrasse 1, 26382 Wilhelmshaven
\end{abstract}

FDOM is one of the most important carriers of anthropogenic compounds in natural waters. It can combine with environmental contaminants and polymers to form diverse chemical structures. To this end, here a microfluidic chip was designed for the analysis of these changes in fluorescent dissolved organic matter (FDOM) fingerprints due to thermal treatment and varying time intervals of exposure. Excitation Emission Matrix Spectroscopy (EEMS) approach was utilized to detect and identify the inherent compounds in sampled FDOM. Strong direct correlations were founded, Spearman rank correlation values $(\rho=0.85$ at $\alpha=0.1, n=4)$ and linear correlation $R^{2}=0.8359$ were noted between thermal treatment pattern 2 and fluorescence intensity of samples. Materials, acrylic based glue and cyclic olefin copolymer (COC) polymer, used to design the microfluidic sensor were determined to possess unique spectral features in the ultraviolet to green spectrum using EEMS. The study therefore provides an insight on methods to identify contaminants in natural waters. This underlines the potential of optical sensors providing measurements at fast intervals, enabling environmental monitoring.

[DOI: http://dx.doi.org/10.2971/jeos.2016.16014]

Keywords: Extraction, polymer, EEMs, plastic, fluorescent DOM, bio-optics, Suwannee river

\section{INTRODUCTION}

Dissolved organic matter (DOM) is a major source of carbon in the aquatic environment $[1,2]$. DOM is a combination of chemical compounds with varying molecular weights, chemical structures that can be generated as a by-product of biodegradation, photochemical and primary production processes [3]. The composition of DOM depends on geographical location, local anthropogenic and industrial activities. Typical compounds found in DOM include lignin, humic and fulvic acid, proteins and amino acid residues $[4,5]$.

Fluorescent Dissolved Organic Matter (FDOM) is a portion of DOM that fluoresces when exposed to ultra-violet light [6]-[8]. FDOM is part of Colored Dissolved Organic Matter (CDOM), and it is known to regulate light over a wide spectrum influencing optical properties and providing a source of carbon for microorganisms metabolism [9]-[12]. Furthermore, FDOM compounds possess unique signatures that have been correlated and are indicative of inherent chemical structures. These properties can undergo modifications depending on physical, microbiological or chemical properties of their surrounding environment [13]. In natural waters, a rise in temperature enhances the kinetic energy available to molecules. These molecules can dissipate the excess energy by translational movement resulting in more intermolecular collision leading to more chemical reactions. Such chemical reactions between labile compounds in FDOM generate new compounds resulting in different fluorescent signatures. As a result of these changes, it is possible to differentiate fresh FDOM from refractory FDOM. Fluorescence emission happens in specific chemical structures capable of absorbing light with subsequent release of it into lower wavelengths at short time intervals, close to 10-8 seconds. Commonly fluorescence takes place in compounds with aromatic rings, although some aliphatic and alicyclic compounds or compounds with double bonds in their structures also exhibit fluorescence emission $[14,15]$.

Excitation Emission Matrix Spectroscopy (EEMS) is an important approach used to categorize FDOM compositions so as to identify different groups of fluorophores [4]. EEMS technique allows the collection of three-dimensional fluorescent spectra to display the composition of main components in the sample. The spectrum is obtained by plotting the intensity signals, against the emission and excitation wavelengths in a 
three dimensional plane. The approach offers very sensitive hyperspectral fluorescence measurements with a high detection limit of FDOM compounds. In prior investigations, EEMS has been key in detecting metals [16], hormones [17], hydrocarbons [18], pesticides [19], surfactants, amino acid residues, proteins, and humic compounds that are part of dissolved organic matter [20]-[22]. Furthermore, spectra from EEMS have been shown to be a reasonable proxy and tracer for primary production and degradation of optically active compounds in natural waters [23]- [25].

The diversity in structures and chemical compounds in FDOM as well as its likely transformation under specific conditions in natural waters makes it a useful indicator of biochemical changes. In estuarine systems, FDOM has been associated as a carrier for certain compounds and chemicals derived from antibiotics, hormones, household and industrial waste [26, 27]. Furthermore, with a rapid increase in plastic debris being released into natural waters there is a need to detect and possibly identify source polymers given that plastics are a nuisance in nature. In this study we therefore assess the EEMS method to identify FDOM ability extracting chemical contaminants from polymeric materials. Thermal treatments in a novel microfluidic device were used to enhance FDOM molecules reactions and extraction process from plastic polymers.

\section{METHODS AND MATERIALS}

\subsection{Design of microfluidic chip}

A custom made microfluidic chip (Figure 1) was developed using printed circuit boards (PCB) and a channel layer. The PCB was a $1.5 \mathrm{~mm}$ thick FR4 and $18 \mu \mathrm{m}$ copper layer and was structured by a wet etching process. $2 \mathrm{~mm}$ cyclic olefin copolymer (COC) Topas 6017S-04 layer was used for the channel element. The $1 \mathrm{~mm}$ wide and $250 \mu \mathrm{m}$ deep channel structure was made with a Minitech MinimillGX CNC controlled micro milling machine. A $50 \mu \mathrm{m}$ thick VHB 9460 3M transfer tape was utilized to attach the PCB and channel layer. The transfer tape is applied to the channel layer first and then aligned to the PCB with the help of aligning posts. Curing is completed in a Thermo- press for 45 minutes at $60^{\circ} \mathrm{C}$ under $2000 \mathrm{kPa}$ pressure. Peltier elements were integrated as thermal setting elements at the back of the PCB in $1.3 \mathrm{~mm}$ pre-milled pockets. In this setup, we assumed minimal thermal resistance [28].

Temperature was well regulated with a 5 second delay to obtain equilibrium (Figure 2). Cold sample was pumped into the hot zone using the syringe pump and then back into the cold zone after thermal treatment.

\subsection{Study area and sample preparation}

Jade Bay (southern North Sea, $53.4500^{\circ} \mathrm{N} 8.2000^{\circ} \mathrm{E}$ ) as part of the Wadden Sea receives contaminants from various transport routes, especially from marine currents and discharges from River Weser. FDOM composition of Jade Bay samples is ruled mainly from these main inputs and its chemical compositions have been studied previously [29]-[31] (Figure 3).

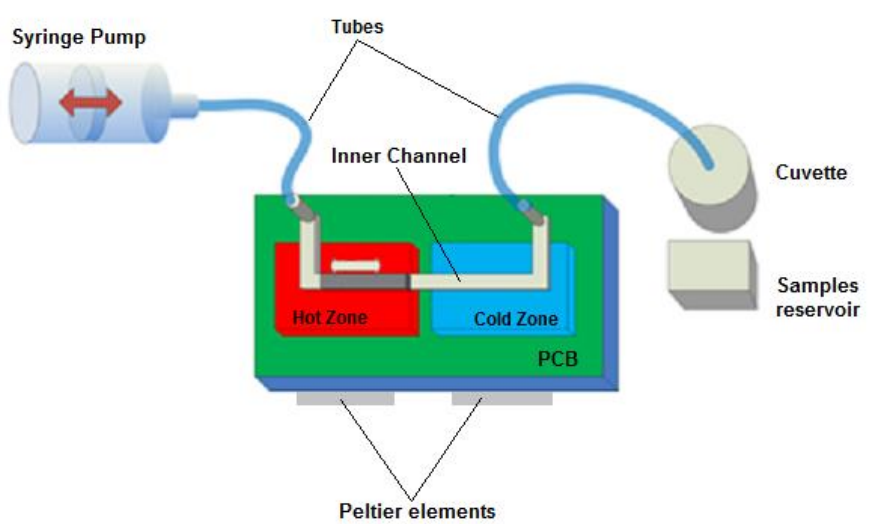

FIG. 1 Schematic design of the microfluidic chip with a bidirectional flow syringe pump and the sample reservoir (adapted from [28]).

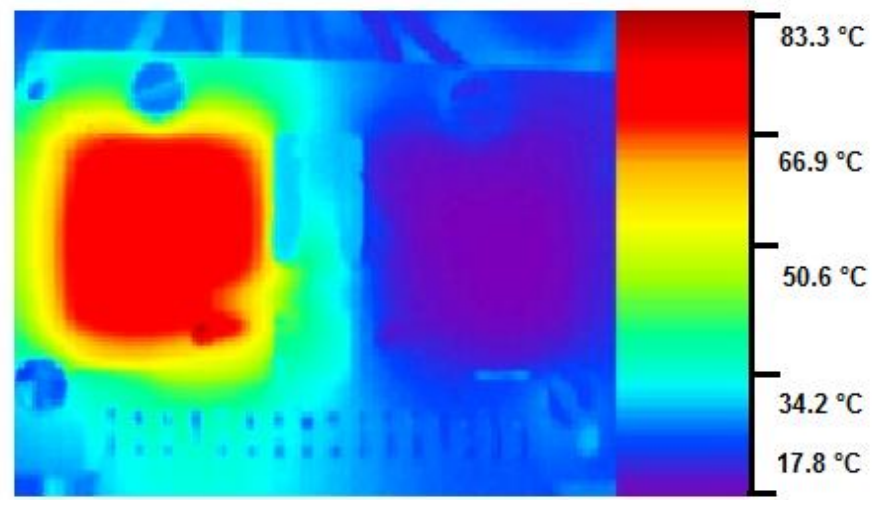

FIG. 2 Prototype thermograph showing thermal isolation of treatment zones. The high temperature zone was heated at $80^{\circ} \mathrm{C}$ the low temperature zone was set at $20^{\circ} \mathrm{C}$. Thermograph was captured when the cold liquid enters the hot zone and shows the temperature control over the treatment zone (adapted from [28]]).

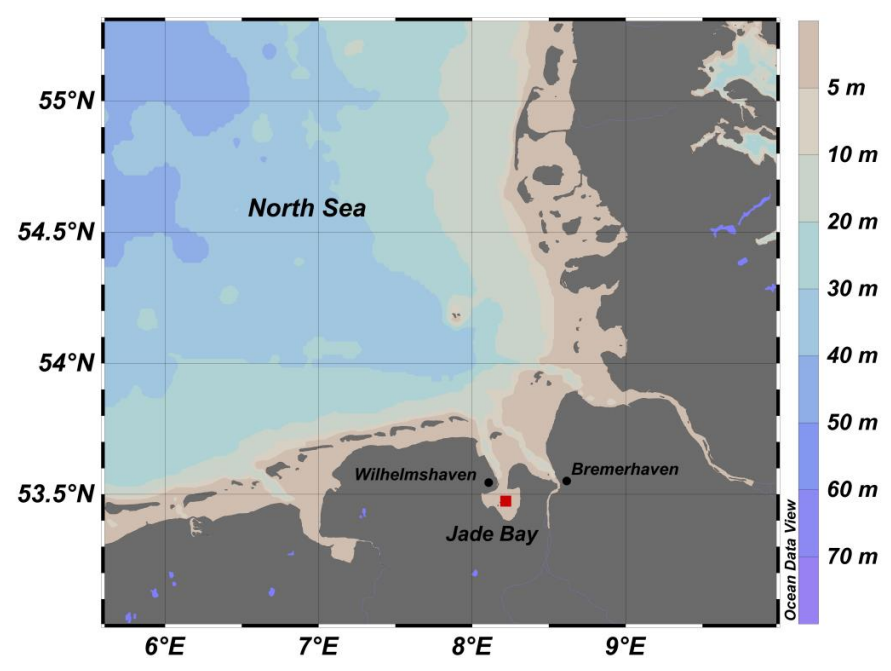

FIG. 3 Study area in Jade Bay, Lower Saxony Wadden Sea.

Surface water samples from Jade Bay were heated from $20^{\circ} \mathrm{C}$ to $90^{\circ} \mathrm{C}$ within the developed microfluidic device. After cooling samples fluorescence intensity was scanned. Two treatment setups (Table 1) were performed with temperatures set to $20^{\circ} \mathrm{C}, 30^{\circ} \mathrm{C}, 70^{\circ} \mathrm{C}$ and $90^{\circ} \mathrm{C}$.

Suwannee River DOM reference material (IHSS, www.humicsubstances.org) was dissolved to obtain concentrations ranging between 724 and $3620 \mu \mathrm{g} / \mathrm{L}$. These 
Treatment $1 \quad 30^{\circ} \mathrm{C}$

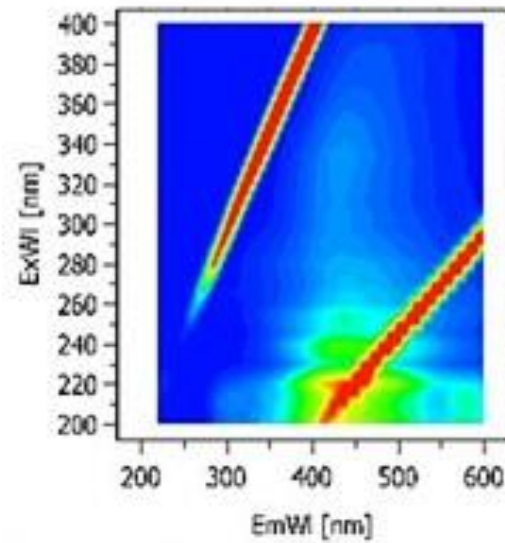

Treatment 2

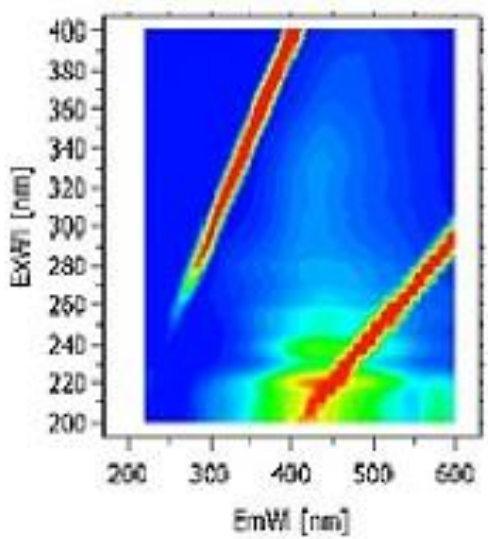

$70^{\circ} \mathrm{C}$
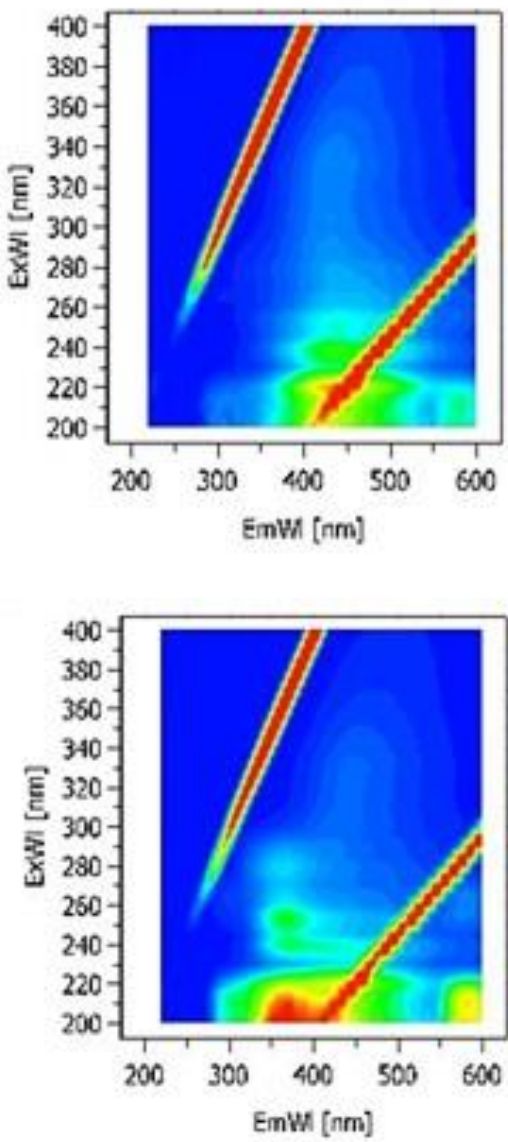

$90^{\circ} \mathrm{C}$
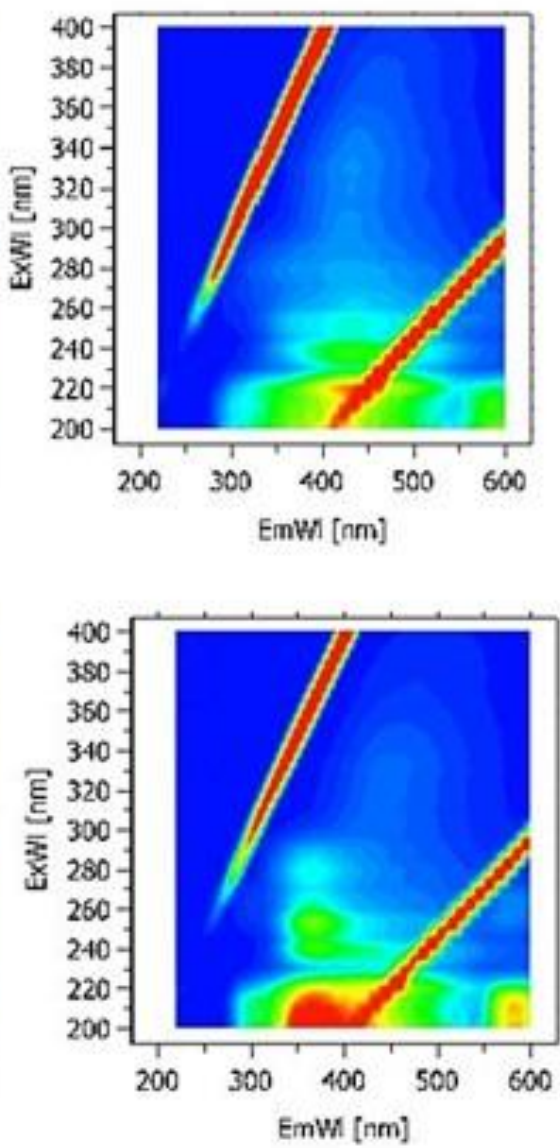

FIG. 4 EEMS spectra for the Jade Bay samples after treatment 1 and treatment 2.

\begin{tabular}{|l|l|l|l|l|}
\hline $\begin{array}{l}\text { Treatment } \\
\text { number }\end{array}$ & Time & $\begin{array}{l}\text { Heating } \\
\text { cycles } \\
\text { (s) }\end{array}$ & $\begin{array}{l}\text { Cooling } \\
\text { cycles }\end{array}$ & $\begin{array}{l}\text { Treatment } \\
\text { time } \\
\text { (s) }\end{array}$ \\
\hline 1 & 60 & 1 & 1 & 60 \\
\hline 2 & 10 & 6 & 6 & 60 \\
\hline
\end{tabular}

TABLE 1 Setup parameters for the microfluidic thermal treatment.

dissolutions were exposed to COC resin and acrylic glue samples for 8 days. After this period fluorescence intensity of samples was recorded. Suwannee river DOM reference standards were prepared freshly by dissolution with deionized water, conductivity of $18.2 \mathrm{M} \Omega$, and stored at $4^{\circ} \mathrm{C}$ in dark bottles.

All samples and standards were filtered through Nucleopore ${ }^{\circledR}$ membrane filters with nominal pore size of $0.2 \mu \mathrm{m}$. Quartz cuvettes and micro cuvettes were rinsed overnight in Helmanex ${ }^{\circledR}$ cleaning solution to remove FDOM remains from internal walls. After cleaning, cuvettes were rinsed with deionized water and dried at room temperature using compressed dry air.

\subsection{EEMS analysis}

Spectrofluorometric measurements were completed immediately after thermal treatment using a $1 \mathrm{~cm}$ quartz cuvette in a Perkin Elmer LS-55 spectrofluorometer. Three dimensional fluorescence spectra of samples and Milli-Q water were de- termined at $10 \mathrm{~nm}$ bandwidth in both excitation and emission, respectively. Excitation wavelength was fixed in a spectral range of $200 \mathrm{~nm}$ to $400 \mathrm{~nm}$, with steps of $5 \mathrm{~nm}$. The emission of fluorescence spectra was recorded over a wavelength range of $200 \mathrm{~nm}$ to $600 \mathrm{~nm}$.

\section{RESULTS AND DISCUSSION}

\subsection{Jade Bay FDOM experiments}

EEMS spectra computed from Jade Bay samples (Figure 4) presented unexpected findings. Fluorescence quenching observed here was considered as an indicator of new chromophoric compounds. The thermal treatment 1 resulted in an unknown signal, excitation at $205 \mathrm{~nm}$ and emission at $580 \mathrm{~nm}$. We rule out the presence of chlorophyll because the samples had been filtered with a 0.2 micron filter. Treatment 2 had similar spectra with an enhanced signal for this unknown compound. The chromophore concentration appeared to have a higher concentration. These findings suggest that there is a link between this chromophoric compound and temperature as well as treatment time. Further analysis was carried out to confirm the correlation between the compound and temperature using Spearman rank correlation test (Figure 5).

Thermal treatment number 2 exhibits a higher extraction effect with respect to heat treatment 1 . In comparing the number of heating cycles in each treatment it is evident that new chromophores accumulate in the sample although with increasing 


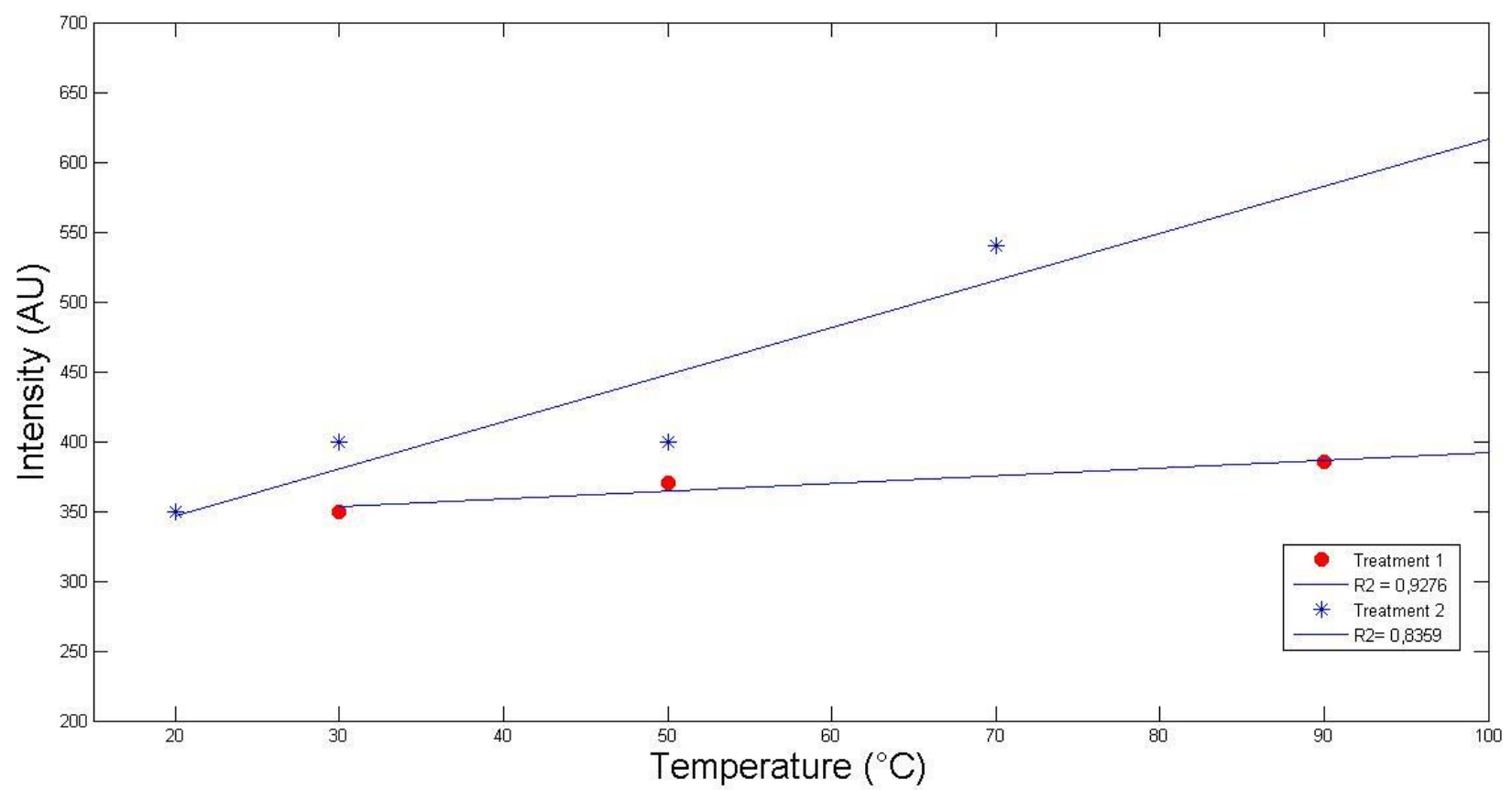

FIG. 5 Linear regression test between temperature and measured intensity for the unknown peak at excitation/emission wavelengths of $205 / 580$ nm, in Jade Bay natural FD0M samples.

Acrylic glue

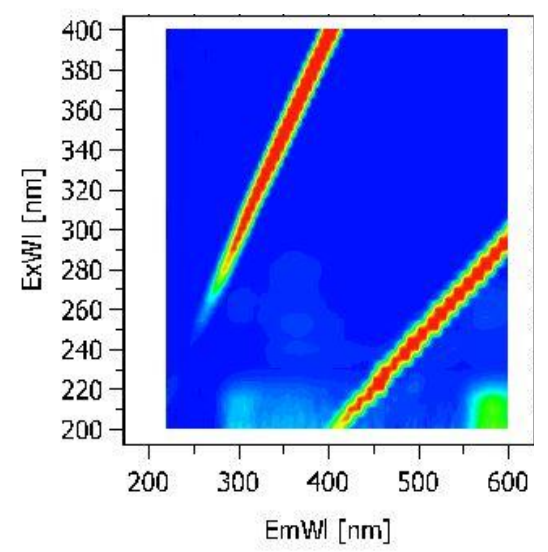

COC polymer

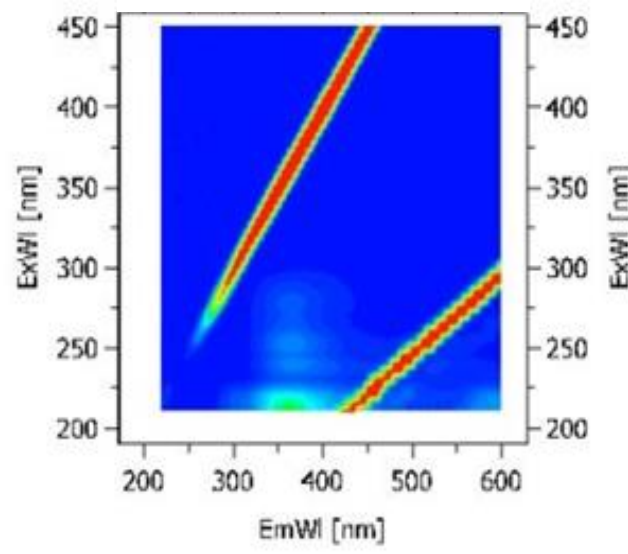

Plastic tube

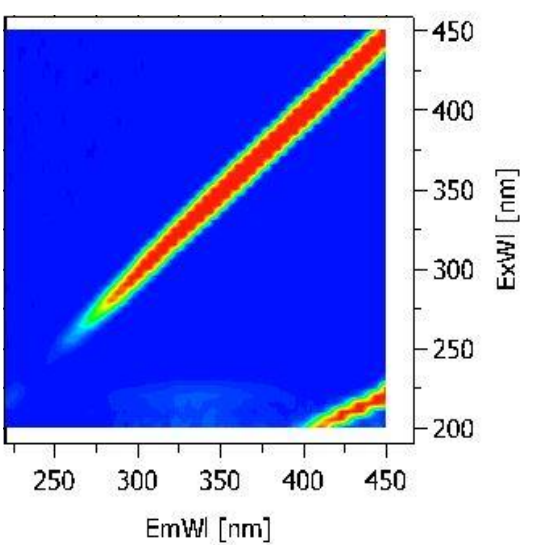

FIG. 6 Fluorescence intensity for new chromophores released by polymeric components used in the fabrication of the microfluidic chip within deionized water.

temperature treatment 2 had a relatively higher enhancement of the chromophore. In general, a strong correlation was evident and investigated using Spearman rank correlation to determine the degree of association. For treatment 2, we found a Spearman coefficient value $\rho=0.85$ for $n=4$ and $\alpha=0.1$, these values suggest the existence of a correlation between intensity of the chromophore and the temperature applied. A linear regression analysis was conducted for both treatments and correlation coefficients support the previous analysis (Figure 5).

\subsection{Identifying polymers in natural FDOM}

In order to identify the possible source of the new compound observed (Figure 4) a study of the raw material used to design the microfluidic sensor was carried out using samples from acrylic glue, COC polymer and plastic tubing submerged in $5.0 \mathrm{~mL}$ deionized water. Each raw material sample was heated up to $70^{\circ} \mathrm{C}$ for 15 minutes and immediately cooled. EEMS was utilized to derive the inherent excitation/emission wavelengths values (Figure 6). The unique EEMS spectra are sum- marized (Table 2), suggesting that the observed feature originated from the acrylic glue used in the construction of the microchip.

Based on these results we think that the detection of polymer or foreign material in FDOM is possible. Foreign materials (polymers tested here) will increase the fluorescence intensity and peaks will be in most cases separable from the well-known peaks [27]. In an effort to quantify the extraction increase from the presence of FDOM we computed the intensity of the new chromophore extracted by natural FDOM compared to the blank analysis both for the acrylic glue and the COC polymer (see Table 3). Here an increase of $16 \%$ to $125 \%$ was noted.

\subsection{Sensitivity analysis of identifying contaminants within FDOM}

An investigation to detect compounds in FDOM alone was completed with samples of COC polymer and the acrylic glue mixed with water samples containing different concentrations 


\begin{tabular}{|c|c|c|c|}
\hline Chromophore signal & $\begin{array}{c}\text { Excitation wavelength } \\
\text { (nm) }\end{array}$ & $\begin{array}{c}\text { Emission wavelength } \\
(\mathbf{n m})\end{array}$ & Description \\
\hline 1 & 205 & 300 & Acrylic glue \\
\hline 2 & 205 & 580 & Acrylic blue \\
\hline 3 & 240 & 375 & COC polymer \\
\hline 4 & 250 & 375 & COC polymer \\
\hline 5 & 280 & 375 & COC polymer \\
\hline
\end{tabular}

TABLE 2 Identification of peaks associated with the sampled polymer used for the microchip construction.

\begin{tabular}{|c|c|c|c|c|c|c|}
\hline \multirow{2}{*}{$\begin{array}{c}\text { Chromophore } \\
\text { signal }\end{array}$} & \multicolumn{2}{|c|}{ Wavelength } & \multicolumn{3}{c|}{ Intensity } & \\
\cline { 2 - 6 } & Excitation & Emission & $\begin{array}{c}\text { Sample } \\
\text { with } \\
\text { FDOM }\end{array}$ & $\begin{array}{c}\text { Acrylic } \\
\text { glue } \\
\text { blank }\end{array}$ & $\begin{array}{c}\text { COC } \\
\text { polymer } \\
\text { blank }\end{array}$ & $\begin{array}{c}\text { Intensity } \\
\text { increment }\end{array}$ \\
\hline 1 & 205 & 300 & 365 & 250 & & \\
2 & 205 & 350 & 675 & & 350 & 93 \\
3 & 205 & 580 & 767 & 390 & & 97 \\
4 & 240 & 375 & 630 & & 280 & 125 \\
5 & 250 & 375 & 360 & & 280 & 29 \\
6 & 280 & 375 & 405 & & 350 & 16 \\
\hline
\end{tabular}

TABLE 3 Fluorescence intensity (arbitrary units) after treatment 2 at $70^{\circ} \mathrm{C}$. An increment indicated changes in the chromophore extraction efficiency through the presence of natural FDOM.
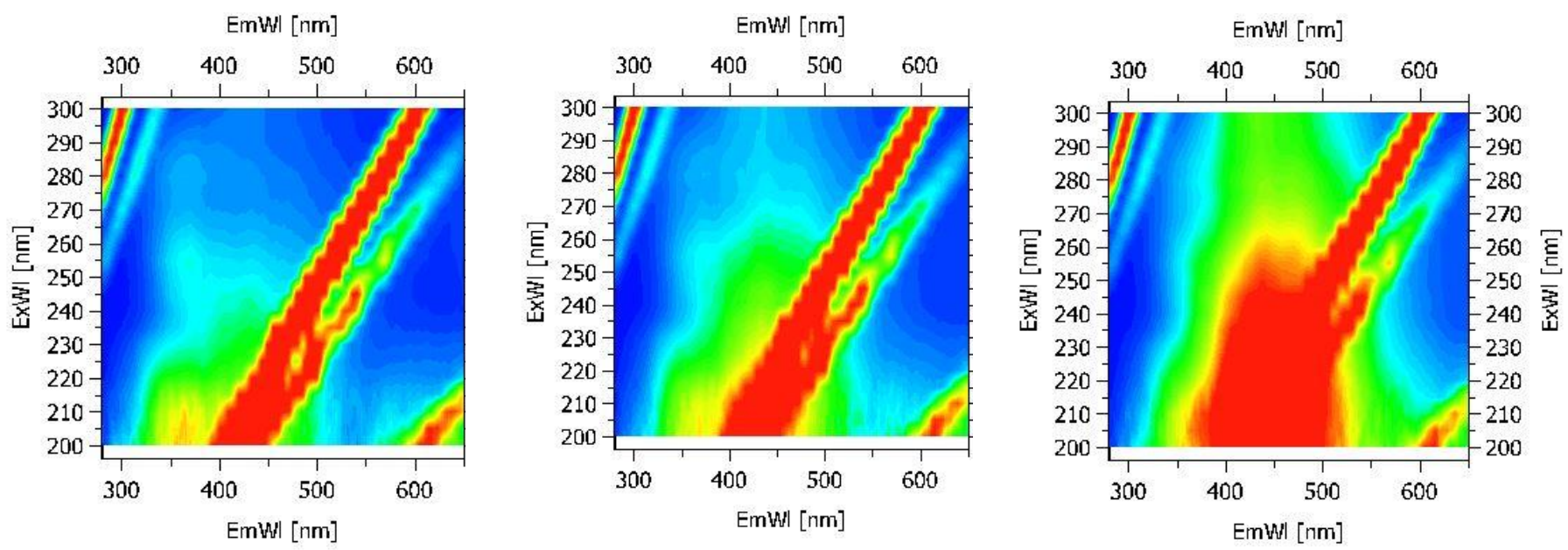

FIG. 7 Extraction of new chromophores as a function of FDOM concentration. After 8 days of exposition, no clear trend for the extraction process was observed (left to right: 724 1448 and $3620 \mu \mathrm{g} / \mathrm{L}$.

of Suwannee river FDOM reference material. The mixed sample was left at room temperature for a week. EEMS was carried out under the same conditions as the treated samples. The correlation between FDOM concentration and the intensity of the unknown peaks in the extraction process in the short time was not clear $\left(R^{2}=0.4808, p=0.05\right)$, although the same peak at $(E x / E m): 205 / 580 \mathrm{~nm}$ was observed (Figure 7).

\section{CONCLUSION}

In this study, chemical compounds from a polymeric based microfluidic device were detected in the presence of FDOM after thermal treatments of natural water samples from Jade Bay and Suwannee River FDOM reference material. A clear correlation between the extraction process of polymeric compounds in presence of natural FDOM and temperature treatment was observed. Same signals from unknown components were detected in samples which remained in contact with the microfluidic device components for a short range of time at ambient temperatures. It was not possible to establish a clear correlation between extraction of polymeric components and the FDOM concentration, but it was observed that the extraction process was improved by the presence of FDOM in samples. Future research will include detailed evaluation of FDOM concentration on the extraction process of plastic monomers in seawater under ambient temperature conditions.

\section{ACKNOWLEDGEMENTS}

This work was performed as part of the DOMsense project funded by the Federal Ministry of Education and Research (KF2866501DF1) in cooperation with TriOS Mess- und Datentechnik GmbH (Germany). M. Miranda acknowledges 
DAAD for the research scholarship (Forschungsstipendien für Doktoranden und Nachwuchswissenschaftler für mehr als 6 Monate, 2014/15, Number 57076385).

\section{References}

[1] N. Nelson, and D. Siegel, "The global distribution and dynamics of chromophoric dissolved organic matter," Annu. Rev. Mar. Sci. 5, 447-476 (2013).

[2] J. I. Hedges, "Global biogeochemical cycles: progress and problems," Mar. Chem. 39, 67-93 (1992).

[3] N. Scully, W. Cooper, and L. Tranvik, "Photochemical effects on microbial activity in natural waters: the interaction of reactive oxygen species and dissolved organic matter," FEMS Microbiol. Ecol. 46, 353-357 (2003).

[4] J. T. 0. Kirk, Light $\Theta$ photosynthesis in aquatic ecosystems (Cambridge University Press, New York, 2011).

[5] 0. Zielinski, and J. Watson (eds.), Subsea optics and imaging (first edition, Woodhead Publishing limited, Cambridge, 2014).

[6] R. Del Vecchio, and N.V. Blough, "Influence of ultraviolet radiation on the chromophoric dissolved organic matter in natural waters," in Environmental UV radiation: impact on ecosystems and human health and predictive models, F. Chetti, G. Checcucci and J. F. Bornman, eds., 203-216, (Springer Netherlands, Dordrecht, 2006).

[7] P. Coble, "Characterization of marine and terrestrial DOM in seawater using excitation-emission matrix spectroscopy,"Mar. Chem. 51, 325-346 (1996).

[8] P. Coble, "Marine optical biogeochemistry: the chemistry of ocean color," Chem. Rev. 107, 402-418 (2007).

[9] F. Jiang, F. S-C. Lee, X. Wang, and D. Dai, "The application of Excitation /Emission Matrix spectroscopy combined with multivariate analysis for the characterization and source identification of dissolved organic matter in seawater of Bohai Sea, China," Mar. Chem. 110, 109-119 (2008).

[10] M.G. Villagarcia, 0. Llinas, R. Reuter, M.J. Rueda, 0. Zielinski, and J. Godoy, "Distribution of gelbstoff fluorescence in the Northern Canary Box," Deep-Sea Res. Pt. II 49, 3497-3511 (2002).

[11] S. P. Garaba, D. Voß, and 0. Zielinski, "Physical, bio-optical state and correlations in North-Western European Shelf Seas," Remote Sens. 6, 5042-5066 (2014).

[12] 0. Zielinski, D. Voß, B. Saworski, B. Fiedler, and A. Körtzinger, "Computation of nitrate concentrations in turbid coastal waters using an in situ ultraviolet spectrophotometer," J. Sea Res. 65 , 456-460 (2011).

[13] E. Boyle, N. Guerreiro, A. Thiallet, R. Del Vecchio, and N. Blough, "Optical properties of humic substances and CDOM: relation to structure," Environ. Sci. Technol. 43, 2262-2268 (2009).

[14] J. R. Lakowicz, Principles of fluorescence spectroscopy (third edition, Springer US, New York, 2006).

[15] C. Moore, A. Barnand, P. Fietzek, M. Lewis, H. Sosik, S. White, and 0 . Zielinski, "Optical tools for ocean monitoring and research," Ocean Sci. 5, 661-684 (2009).

[16] F. Degryse, E. Smolders, and D. R. Parker, "Partitioning of metals $(\mathrm{Cd}, \mathrm{Co}, \mathrm{Cu}, \mathrm{Ni}, \mathrm{Pb}, \mathrm{Zn})$ in soils: concepts, methodologies, prediction and applications - a review," Eur. J. Soil Sci. 60, 590-612, (2009).

[17] S. Nardi, D. Pizzeghello, L. Bragazza, and R. Gerdol, "Low- molecular weight organic acids and hormone-like activity of dissolved organic matter in two forest soils in N Italy," J. Chem. Ecol. 29, 1549-1564 (2003).

[18] E. Baszanowska, 0. Zielinski, Z. Otremba, and H. Toczek, "Influence of oil-in-water emulsions on fluorescence properties as observed by excitation-emission spectra," J. Eur. Opt. Soc.-Rapid. 8, 13069 (2013).

[19] D. Said-Pullicino, G. Gigliott, and A. Vella, "Environmental fate of triasulfuron in soils amended with municipal waste compost," J. Environ. Qual. 33, 1743-1751 (2004).

[20] P. Sánchez-Marín, J. Santos-Echeandía, M. Nieto-Cid, X. A. ÁlvarezSalgado, and R. Beiras, "Effect of dissolved organic matter (DOM) of contrasting origins on $\mathrm{Cu}$ and $\mathrm{Pb}$ speciation and toxicity to Paracentrotus lividus larvae," Aquat. Toxicol. 96, 90-102 (2010).

[21] F. Yang, M. Wang, and Z. Wang, "Sorption behavior of 17 phthalic acid esters on three soils: effects of $\mathrm{pH}$ and dissolved organic matter, sorption coefficient measurement and QSPR study," Chemosphere 93, 82-89 (2013).

[22] J. M. Marín-Benito, C. D. Brown, E. Herrero-Hernández, M. Arienzo, M. J. Sánchez-Martín, and M. S. Rodríguez-Cruz, "Use of raw or incubated organic wastes as amendments in reducing pesticide leaching through soil columns," Sci. Total Environ. 463-464, 589-599 (2013).

[23] R. Jaffé, K. Cawley, and Y. Yamashita, "Applications of excitation emission matrix fluorescence with parallel factor analysis (EEMPARAFAC) in assessing environmental dynamics of natural dissolved organic matter (DOM)," in Aquatic environments: a review. Advances in the physicochemical characterization of dissolved organic matter: impact on natural and engineered systems, Fernando Rosario-Ortiz, ed., 27-73 (first edition, 0xford University Press, Colorado, 2014).

[24] P. Coble, "Characterization of marine and terrestrial DOM in seawater using excitation emission matrix spectroscopy," Mar. Chem. 51, 325-346 (1996).

[25] 0. Zielinski, J. A. Busch, A. D. Cembella, J. Engelbrektsson, A. K. Hannides, and H. Schmidt, "Detecting marine hazardous substances and organisms: sensors for pollutants, toxins, and pathogens," Ocean Sci. 5, 329-349 (2009).

[26] D. Kolpin, E. Furlong, M. Meyer, E. Thurman, S. Zaugg, L. Barber, and H. Buxton, "Pharmaceuticals, hormones and other organic wastewater contaminants in U. S. streams 1999-2000: a national reconnaissance," Environ. Sci. Technol. 36, 1202-1211 (2002).

[27] R. W. P. M. Laane , A. D. Vethaak, J. Gandrass, K. Vorkamp, A. Köhler, M. M. Larsen, and J. Strand, "Chemical contaminants in the Wadden sea: sources, transport, fate and effects," J. Sea Res. 82, 10-53 (2002).

[28] S. Gassmann, A. Trozjuk, J. Singhal, H. Schuette, M. L. Miranda, and 0 . Zielinski, "PCB based micro fluidic system for thermal cycling of seawater samples," in Proceedings to IEEE International Conference Industrial Technology (ICIT), 3365-3369 (IEEE, Seville, 2015).

[29] G. Liebezeit, T. Kraul, and B. Everts, "Bulk chemical characterization of particulate material from the Jade Bay, lower Saxonian Wadden Sea," Neth. J. Aquat. Ecol. 28, 365-370 (1994).

[30] H. Jin, G. Liebezeit, and D. Ziehe, "Distribution of total mercury in surface sediments of the Western Jade Bay, Lower Saxonian Wadden Sea, Southern North Sea," Bull. Environ. Contam. Toxicol. 88, 597-604 (2012).

[31] S. Weigel, J. Kuhlmann, and H. Hühnerfuss, “Drugs and personal care products as ubiquitous pollutants: occurrence and distribution of clofibric acid, caffeine and DEET in the North Sea," Sci. Total Environ. 295, 131-141 (2002). 